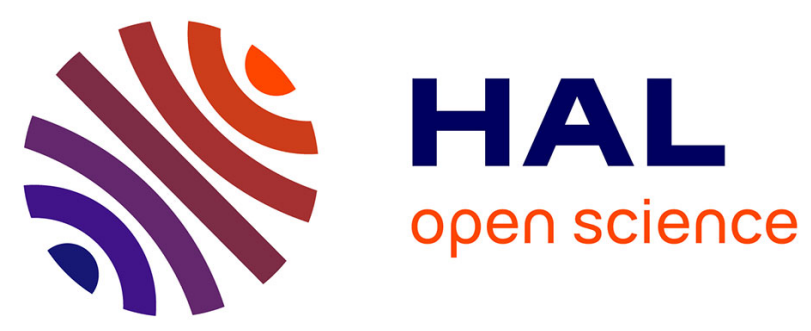

\title{
Comparison of the HDO cycle in the LMD Mars GCM with ACS/TGO observations
}

Loïc Rossi, Margaux Vals, Franck Montmessin, Juan Alday, Ashwin Braude, François Forget, Ehouarn Millour, Kevin Olsen, Anna Fedorova, Alexander Trokhimovskiy, et al.

\section{To cite this version:}

Loïc Rossi, Margaux Vals, Franck Montmessin, Juan Alday, Ashwin Braude, et al.. Comparison of the HDO cycle in the LMD Mars GCM with ACS/TGO observations. European Planetary Science Congress. EPSC 2021, Sep 2021, virtual Meeting, France. 10.5194/epsc2021-281 . insu-03311540

\section{HAL Id: insu-03311540 \\ https://hal-insu.archives-ouvertes.fr/insu-03311540}

Submitted on 1 Aug 2021

HAL is a multi-disciplinary open access archive for the deposit and dissemination of scientific research documents, whether they are published or not. The documents may come from teaching and research institutions in France or abroad, or from public or private research centers.
L'archive ouverte pluridisciplinaire HAL, est destinée au dépôt et à la diffusion de documents scientifiques de niveau recherche, publiés ou non, émanant des établissements d'enseignement et de recherche français ou étrangers, des laboratoires publics ou privés. 
EPSC Abstracts

Vol. 15, EPSC2021-281, 2021, updated on 30 Jul 2021

https://doi.org/10.5194/epsc2021-281

European Planetary Science Congress 2021

(c) Author(s) 2021. This work is distributed under

the Creative Commons Attribution 4.0 License.

\section{Comparison of the HDO cycle in the LMD Mars GCM with ACS/TGO observations}

Loïc Rossi ${ }^{1}$, Margaux Vals ${ }^{1}$, Franck Montmessin ${ }^{1}$, Juan Alday ${ }^{2}$, Ashwin Braude ${ }^{1}$, François Forget ${ }^{3}$, Ehouarn Millour ${ }^{3}$, Kevin Olsen ${ }^{2}$, Anna Fedorova ${ }^{4}$, Alexander Trokhimovskiy ${ }^{4}$, and Oleg Korablev ${ }^{4}$

${ }^{1}$ LATMOS, Université Paris-Saclay, UVSQ, CNRS, Guyancourt, France (loic.rossi@latmos.ipsl.fr)

${ }^{2}$ Department of Physics, University of Oxford, UK

${ }^{3}$ Laboratoire de Météorologie Dynamique (LMD), Sorbonne Université, CNRS, Paris, France

${ }^{4}$ Space Research Institute (IKI), Moscow, Russia

$\mathrm{HDO}$ and the $\mathrm{D} / \mathrm{H}$ ratio are important in order to understand Mars past and present climate, in particular regarding the evolution through ages of the Martian water cycle.

We present simulations of the HDO cycle with the LMD Mars GCM and compare the retrieved cycle with observations provided by the Atmospheric Chemistry Suite (ACS) on board the ESA/Roscosmos Trace Gas Orbiter (TGO).

This work is a companion study of Vals et al. presented in session TP12, which presents the evolutions of the model since Rossi et al, (2021), and explores the behaviour of the D/H ratio cycle when taking into account the microphysics and radiative effect of clouds, as well as the effect of kinetics on fractionation during condensation.

\section{Introduction}

Mars is known to have had a significant liquid water reservoir on the surface and the $\mathrm{D} / \mathrm{H}$ ratio derived from the $\mathrm{HDO} / \mathrm{H}_{2} \mathrm{O}$ abundance ratio is a sensitive tool to constrain the primordial abundance of the water reservoir on Mars and its evolution with time. The current ratio is at least five times that of the Vienna Standard Mean Ocean Water (SMOW) (Owen et al. 1988 , Encrenaz et al. 2018, Krasnopolsky 2015, Villanueva et al. 2015).

$\mathrm{H}$ and $\mathrm{D}$ atoms in the upper atmosphere come from $\mathrm{H} 2 \mathrm{O}$ and $\mathrm{HDO}$, their sole precursor in the lower atmosphere. The lower mass of $\mathrm{H}$ over $\mathrm{D}$ atoms and the fact that $\mathrm{H}_{2} \mathrm{O}$ is preferentially photolysed over HDO (Cheng et al. 1999) explain the differential escape of these two elements. Also, the heavier isotope, HDO, has a lower vapor pressure than $\mathrm{H}_{2} \mathrm{O}$, which results in an enrichment of the deuterated isotope in the solid phase of water. This effect is known as the Vapor Pressure Isotope Effect (VPIE) and can reduce the D/H ratio above the condensation level to values as low as $10 \%$ of the $\mathrm{D} / \mathrm{H}$ ratio near the surface (Bertaux et al. 2001, Fouchet et al. 2000). Fractionation should affect the amount of HDO depending on latitude, longitude, altitude and season (Montmessin et al. 2005, Rossi et al. 2021).

\section{Modeling HDO}


We present here the results from our (re)integration of the HDO cycle into the LMD Mars GCM, taking into account HDO in its vapour and ice phases in the atmosphere, and as surface ice. In Rossi et al. (2021), we presented first results with a dust annual scenario mimicking the dust seasonal and spatial evolution observed during Martian Year 34 (MY34) and including the occurrence of the Global Dust Storm (GDS).

The simulations illustrated the effect of the dust on the temperature field, and therefore on the circulation and the cloud formation. Since clouds are forming at higher altitude (if at all), the deuterium is less constrained vertically and can extend to higher altitudes. A similar effect being observed for water vapour (Fedorova et al., 2020).

In Rossi et al. (2021) we used a simplified cloud formation scheme, without condensation nuclei, and didn't include the radiative effect of clouds.
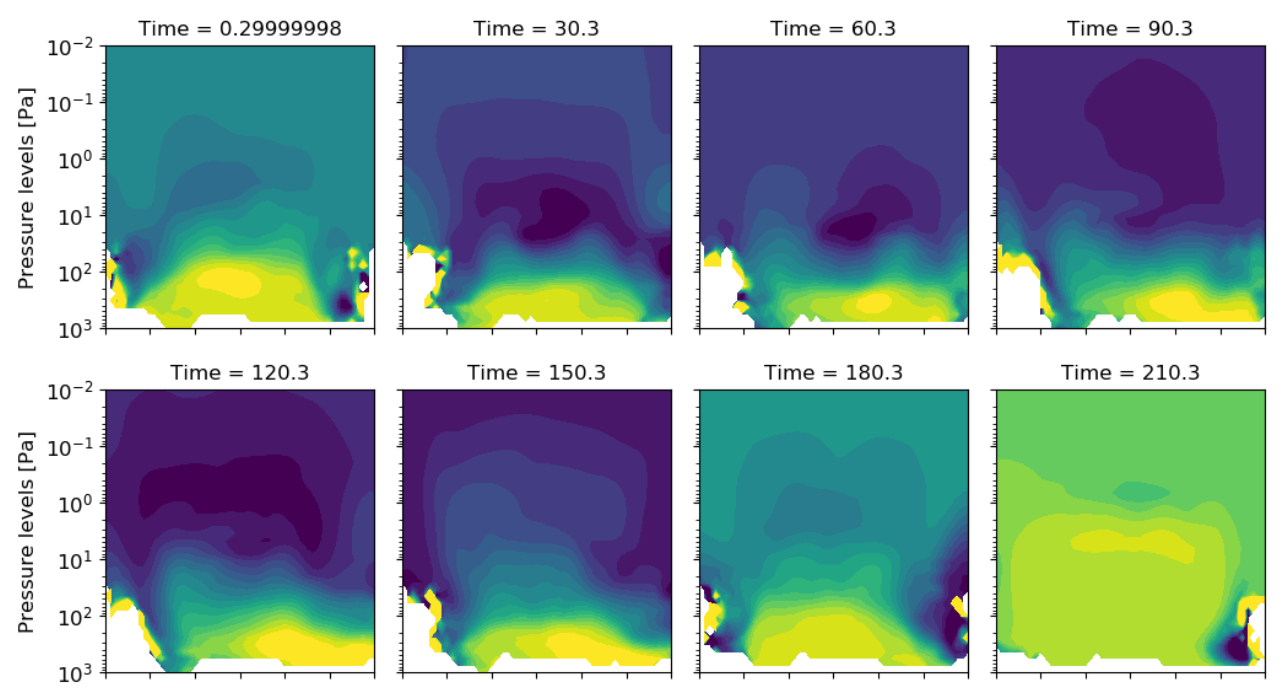

Time $=150.3$

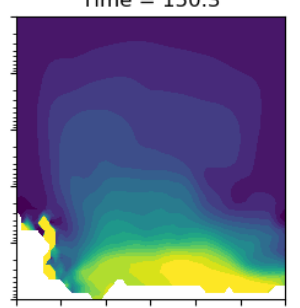

Time $=180.3$

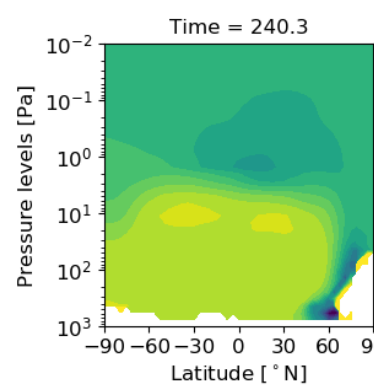

Time $=270.3$

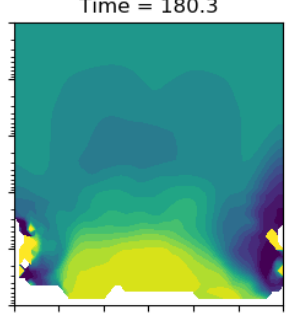

Time $=210.3$

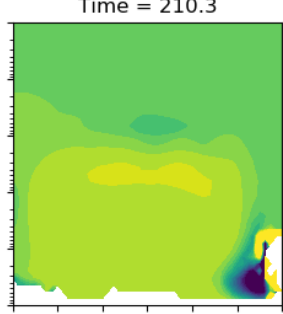

Time $=330.3$
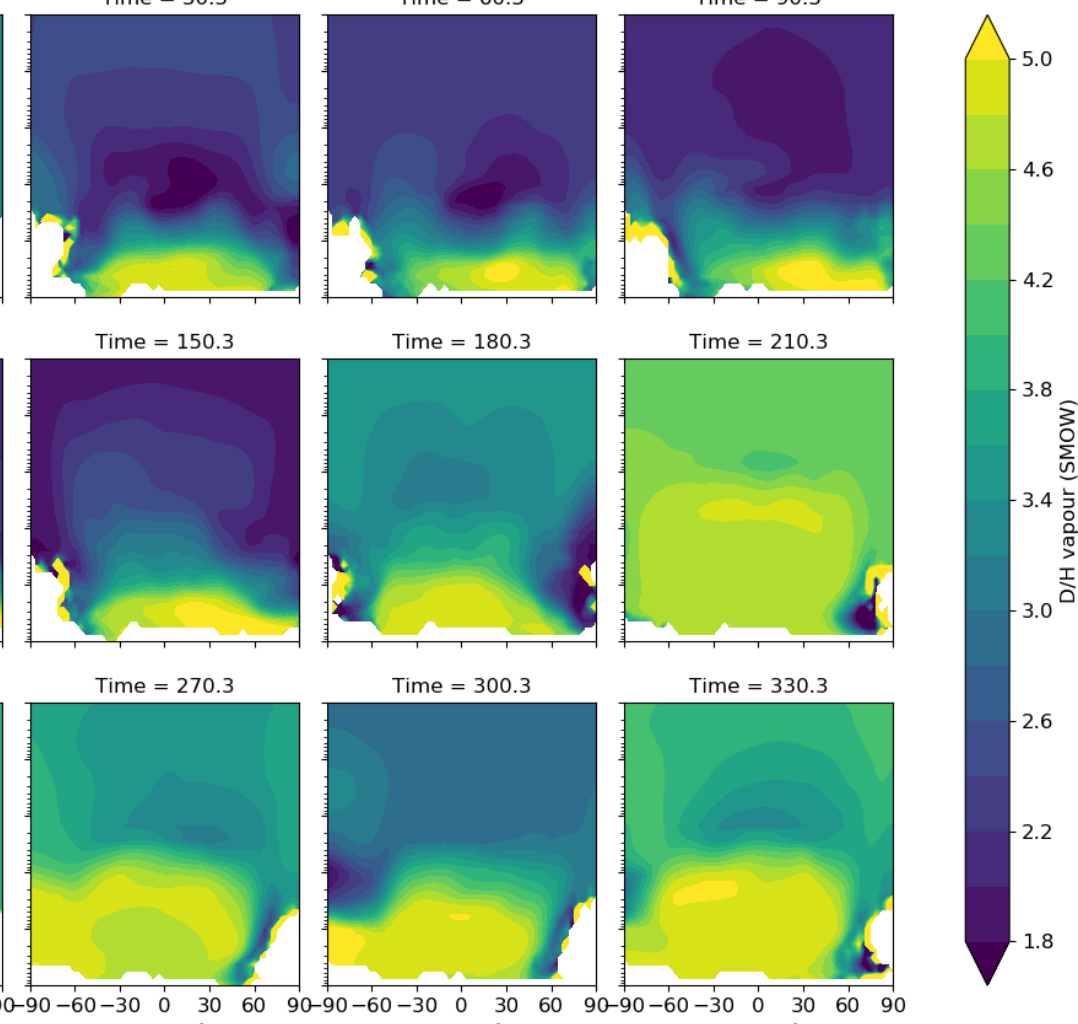

Figure 1: Zonally averaged meridional profiles of the $D / H$ ratio in the vapour phase, as predicted by the updated GCM for MY34. Each subplot shows the beginning of each month.

Here we present results of a new version of the model, this time including the microphysics of cloud formation, the radiative effect of clouds but also the effect of kinetics on the fractionation factor (see companion abstract of Margaux Vals in TP12). As shown in Fig 1, the effect of the dust storm of MY34 is still quite visible, with a $\mathrm{D} / \mathrm{H}$ ratio relatively constant in higher parts of the atmosphere (up to $1 \mathrm{~Pa}$ ). With this updated model, we are able to make comparisons with the HDO profiles observed by ACS onboard TGO.

\section{Preliminary results}

In order to be comparable with the solar occultations from ACS, the GCM output is interpolated at a solar zenith angle of $90^{\circ}$ and at the coordinates (latitude, longitude, local time and solar longitude) of each solar occultation. In particular, we compare the model with ACS observations presented in 
Alday et al. (2021). Figure 2 presents some early results of such comparison.
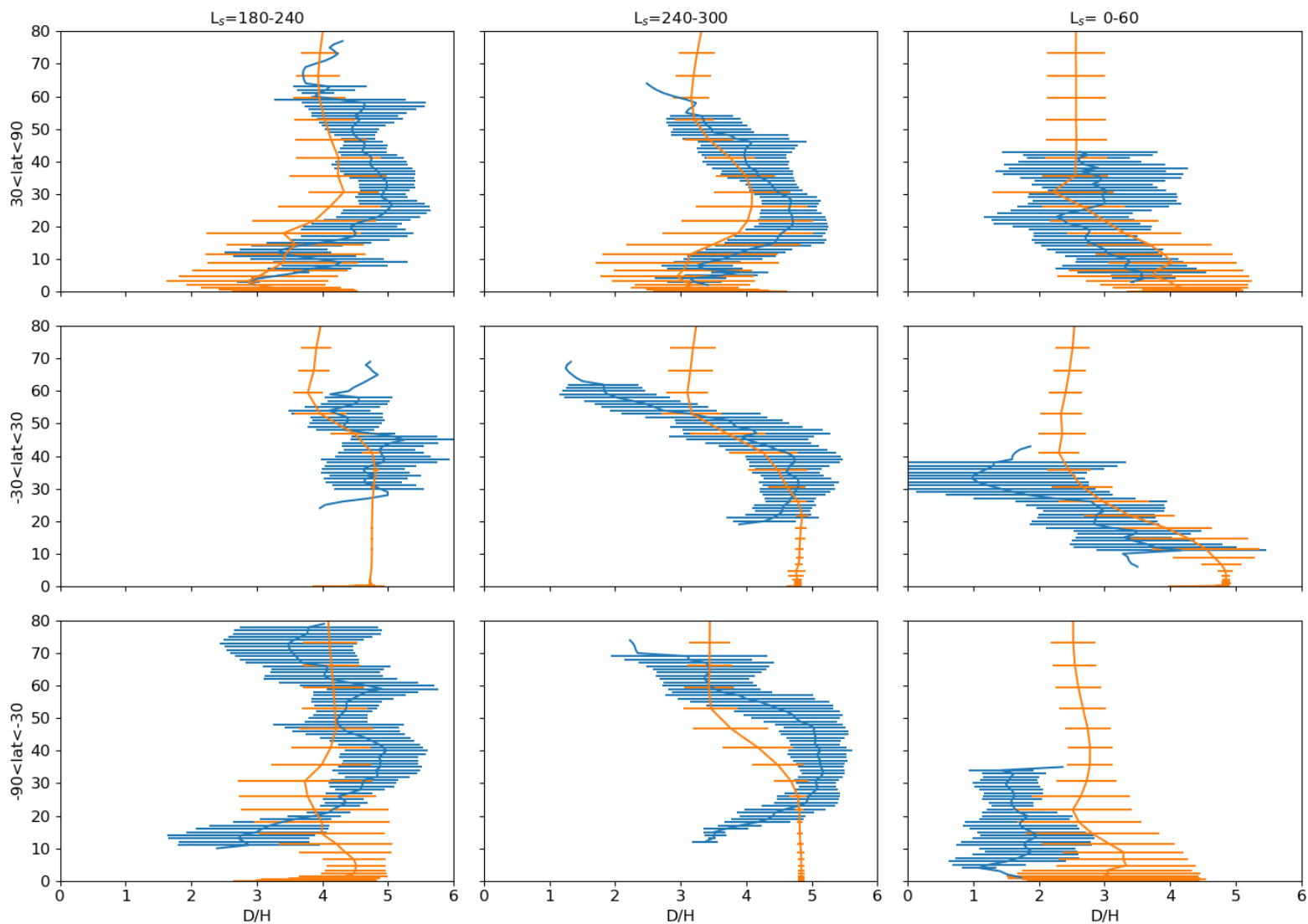

Figure 2: Profiles of the $D / H$ ratio from the GCM (in orange) and from ACS data (in blue). Profiles are averaged over bins of solar longitude (covering the end of MY34 and the beginning of MY35) and latitude. Error bars indicate the standard deviation within the bin. The altitude is given in kilometers above the areoid.

The comparison shows a good agreement between the GCM profiles and the observations for the $\mathrm{D} / \mathrm{H}$ ratio in several bins in latitude and solar longitude. This indicates that the model is capable of representing the process of isotopic fractionation and its effect on the $\mathrm{D} / \mathrm{H}$ ratio.

A more detailed comparison between the observations and the GCM, in particular with respect to the distribution of water vapour is ongoing.

\section{Acknowledgements}

ExoMars is the space mission of ESA and Roscosmos. The ACS experiment is led by IKI Space Research Institute in Moscow. The project acknowledges funding by Roscosmos and CNES. Science operations of ACS are funded by Roscosmos and ESA. Science support in IKI is funded by Federal agency of science organizations (FANO). L.R. acknowledges support from CNES and from the Excellence Laboratory "Exploration Spatiale des Environnements Planétaires (ESEP)". 